\title{
BEHAVIOR OF AXIALLY LOADED CIRCULAR R.C. COLUMN CONFINED WITH CFRP WRAPPING SHEET
}

\author{
Omar Ahmed Farghal Ahmed and Abd El-Rahman Megahid \\ Civil Engineering Department, Faculty of Engineering, Assiut University, \\ Assiut, EGYPT
}

(Received May 10, 2006 Accepted May 30, 2006)

\begin{abstract}
Wrapping of R.C. column by means of Fiber Reinforced Polymer (FRP) reinforcement can significantly improves its structural behavior. The efficiency of this strengthening technique depends mainly upon the encountered parameters related to the original conditions of the element to be strengthened as well as upon both the volume and configuration of the wrapped reinforcement. Such parameters include concrete strength, percentage of longitudinal reinforcement, volume of internal stirrups, shape of cross-section, volume of wrapped reinforcement and arrangements of wrapped sheets. Therefore, an experimental program including seven circular columns is set-up and tested under axial compression load to evaluate the suggested strengthening technique applied to strengthen R.C. columns by means of wrapping Carbon Fiber Reinforced Polymer (CFRP) sheets. The parameters studied through this paper are the arrangements and volume of wrapped CFRP sheets as well as the volume of internal stirrups along these columns. The obtained results are used to evaluate some specific problems in the modeling of CFRP confined concrete, i.e. effective circumferential strain induced in the wrapped CFRP sheets at failure and effect of confining action. Also, the obtained experimental results together with a proposed modified mathematical model are organized in order to investigate the contribution of the externally bonded wrapped CFRP sheets to the load carrying capacity and structural ductility of the strengthened columns. The proposed modified model is based on the expression suggested by the authors to predict the effective circumferential strain induced in the wrapped CFRP sheets at failure. Moreover, an analytical verification of the obtained test results was performed according to the modified proposed model.
\end{abstract}

Both load carrying capacity and structural ductility of R.C. columns improved considerably when applying the proposed strengthening technique. Also, the proposed modified mathematical models suggested to predict the strength of R.C. columns strengthened with wrapped CFRP sheets showed a considerable approach to the results obtained experimentally.

KEYWORDS: Carbon Fiber Reinforced Polymer (CFRP) sheets; wrapping; ductility. 


\section{INTRODUCTION}

Fiber Reinforced Plastics (FRP), a combination of fibers and a matrix, are used as Carbon Fiber (CF), Armid Fiber (AF) and Glass Fiber (GF) reinforced materials. Externally bonded Carbon Fiber Reinforced Plastics (CFRP) sheets are particularly suitable for strengthening and repairing of reinforced concrete structural elements due to the superior properties of CFRP sheets against corrosion, chemicals and environmental attack. Also, the technique of externally bonded CFRP sheets is very simple to be applied in a wide variety without any difficulties, which is considered from the principals when applying the alternative techniques e.g. steel plate technique. Moreover, CFRP sheets are very easy to be cut and wrapped in order to be applied as either closed stirrups or U-jacket strips.

Concrete columns have an important function in the structural concept of many structures. Often these columns are vulnerable to load increase (increasing use or change of structures' function, etc.), exceptional loads (such as: impact; explosion or seismic loads) and degradation (corrosion of steel reinforcement, alkali silica reaction, etc.). Confining of concrete elements by means of wrapping CFRP sheets is considered very efficient to enhance both load carrying capacity and structural ductility of R.C. columns subjected to axial compression load. Also, the efficiency of the externally bonded CFRP sheets in terms of structural performance and ease of application has been demonstrated. Hence, strengthening of concrete columns by means of CFRP wrapping sheets is an attractive technique as evidenced by several research program and practical application $[1,2]$.

Tests on a group of R.C. columns with externally bonded CFRP wrapped sheets have been conducted to study the contribution of the wrapped reinforcement to both the load carrying capacity and structural ductility of the strengthened columns. The wrapped sheets are applied to cover either the whole concrete surface of the column (fully wrapping) or parts of it (partially wrapping in terms of a number of strips distributed along the height of the column). Moreover, the circumferential strain induced in the wrapped CFRP sheets at failure was studied and compared with the predicted results according to the available models [3]. As a result, and on the basis of the obtained results, the authors suggest an expression to accommodate the expected results and to treat the problems in the available models. Also, a modified model was proposed to predict the load carrying capacity of the strengthened columns. The modified model is based on the expression suggested by the authors to predict the effective circumferential strain induced in the wrapped CFRP sheets at failure. As a consequence, the objective of this study was to investigate - analytically and experimentally - the contribution of CFRP wrapping sheets to the load carrying capacity of the strengthened columns. Also, the influence of the CFRP wrapping sheets on both structural ductility and occurred failure mode of the strengthened columns was studied.

\section{EXPERIMENTAL STUDIES}

\section{Layout of Experiments and Materials}

Testing on seven R.C. columns confined with CFRP sheets and subjected to axial loading was performed, see Table 1. The tested columns have a circular cross-section 
of $150 \mathrm{~mm}$ in diameter and $1000 \mathrm{~mm}$ total height. The columns were reinforced with four longitudinal deformed bars $A_{s}, 4 \Phi 10 \mathrm{~mm}$, (Steel 360/520) and provided with ten closed stirrups (Steel 240/350) of $6 \mathrm{~mm}$ in diameter and spacing of $30 \mathrm{~mm}$ at the ends (five stirrups per end along a distance of $120 \mathrm{~mm}$ ) to strengthen the end zones, see Fig. 1. No internal stirrups are provided along the middle $700 \mathrm{~mm}$ for columns C.1-0, C.11, C.1-2, C.1-3and C.1-4. However, internal stirrups of $6 \mathrm{~mm}$ in diameter and $140 \mathrm{~mm}$ spacing are provided for columns C.2-O and C.2-1, see Fig. 1 and Table 1.

Columns C.1-O and C.2-O were tested in their original condition as a control ones (without strengthening). Columns C.1-1 and C.2-1 were confined with five CFRP strips (one ply) with $0^{\circ}$ fiber orientation each of $75 \mathrm{~mm}$ width and $81 \mathrm{~mm}$ free spacing, see Fig. 2. Column C.1-2 was strengthened with seven CFRP strips (one ply) with $0^{o}$ fiber orientation each of about $54 \mathrm{~mm}$ width and $54 \mathrm{~mm}$ free spacing, see Fig. 2. Column C.1-3 was strengthened with five CFRP strips (two plies) with $0^{\circ}$ fiber orientation each of $75 \mathrm{~mm}$ width and $81 \mathrm{~mm}$ free spacing, see Fig. 2. However, Columns C.1-4 was fully wrapped with CFRP sheet (one ply) with $O^{\circ}$ fiber orientation, see Fig. 2. During testing, the ends of the columns were provided with externally steel (mild steel of grade $=370 \mathrm{MPa}$ ) rings (one per each end) of $140 \mathrm{~mm}$ width and $3 \mathrm{~mm}$ thickness.

The tested columns were manufactured by using a concrete mix achieving mean compressive strength $\left(f_{c}\right)$ of $30.0 \mathrm{~N} / \mathrm{mm}^{2}$. The mean compressive strength for the standard cylinder $\left(f_{c}^{\prime}\right)$ at the time of testing (about seven weeks) is listed in Table $\mathbf{1}$ for the different tested columns.

Table 1: Data of tested columns.

\begin{tabular}{|c|c|c|c|c|}
\hline \multirow{2}{*}{$\begin{array}{c}\text { Column } \\
\text { No. }\end{array}$} & \multicolumn{3}{|c|}{ Column Data } & \multirow{2}{*}{ Strengthening System } \\
\hline & $\underset{\left(\mathrm{N} / \mathbf{m m}^{2}\right)}{f_{c}^{\prime}}$ & $A_{S}$ & $\begin{array}{l}\text { Internal } \\
\text { Stirrups }\end{array}$ & \\
\hline C.1-0 & 24.2 & \multirow{7}{*}{$4 \Phi 10 \mathrm{~mm}$} & \multirow{5}{*}{$\begin{array}{l}\text { No internal } \\
\text { stirrups } \\
\text { provided }\end{array}$} & Control Column 1 \\
\hline C.1-1 & 24.9 & & & $\begin{array}{l}\text { Partially wrapping: } 5 \text { CFRP strips, each of } 75 \\
\text { mm width and } 81 \mathrm{~mm} \text { free spacing (one ply, } \\
\rho_{\mathrm{f}} \approx 1.67 \% \text { ), see Fig. } 2\end{array}$ \\
\hline C.1-2 & 24.9 & & & $\begin{array}{l}\text { Partially wrapping: } 7 \text { CFRP strips, each of } 54 \\
\text { mm width and } 54 \mathrm{~mm} \text { free spacing (one ply, } \\
\rho_{\mathrm{f}} \approx 1.67 \% \text { ), see Fig. } 2\end{array}$ \\
\hline C.1-3 & 27.4 & & & $\begin{array}{l}\text { Partially wrapping: } 5 \text { CFRP strips, each of } 75 \\
\text { mm width and } 81 \mathrm{~mm} \text { free spacing (two plies, } \\
\rho_{\mathrm{f}} \approx 3.33 \% \text { ), see Fig. } 2\end{array}$ \\
\hline C.1-4 & 24.2 & & & $\begin{array}{l}\text { Fully wrapping (one ply, } \rho_{\mathrm{f}} \approx 3.47 \% \text { ), see } \\
\text { Fig.2 }\end{array}$ \\
\hline C.2-0 & 24.4 & & \multirow[b]{2}{*}{$\begin{array}{c}1 \varphi 6 \mathrm{~mm} \\
@ 140 \mathrm{~mm}\end{array}$} & Control Column 2 \\
\hline C.2-1 & 24.4 & & & $\begin{array}{l}\text { Partially wrapping: } 5 \text { CFRP strips, each of } 75 \\
\text { mm width and } 81 \mathrm{~mm} \text { free spacing (one ply } \rho_{\mathrm{f}} \\
\approx 1.67 \% \text { ), see Fig. } 2\end{array}$ \\
\hline
\end{tabular}




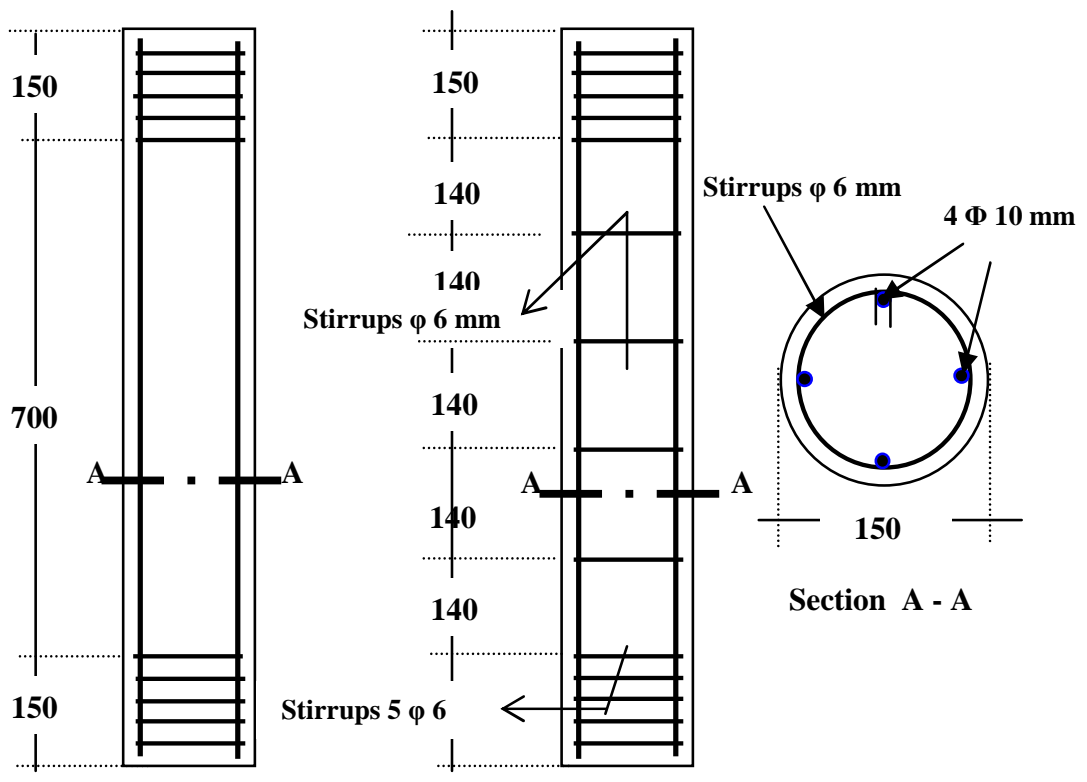

Columns C.1-0 to C.1-4 Columns C.2-0 and C.2-1

Fig. 1: Details of internal reinforcement for tested columns.

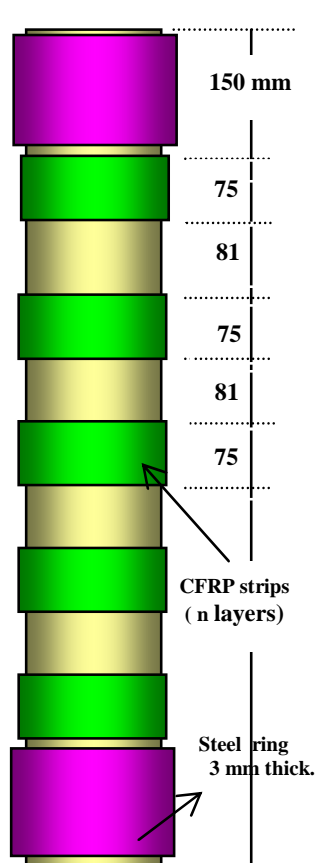

Columns C.1-1, C.1-3 and C.2-1

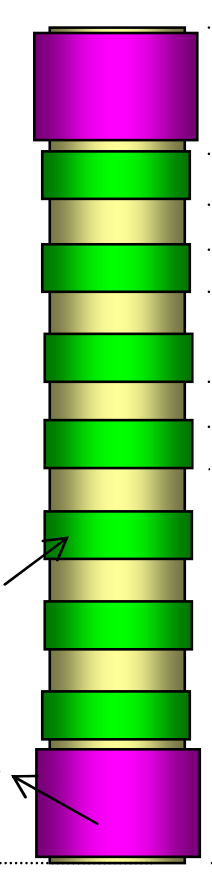

Column C.1-2

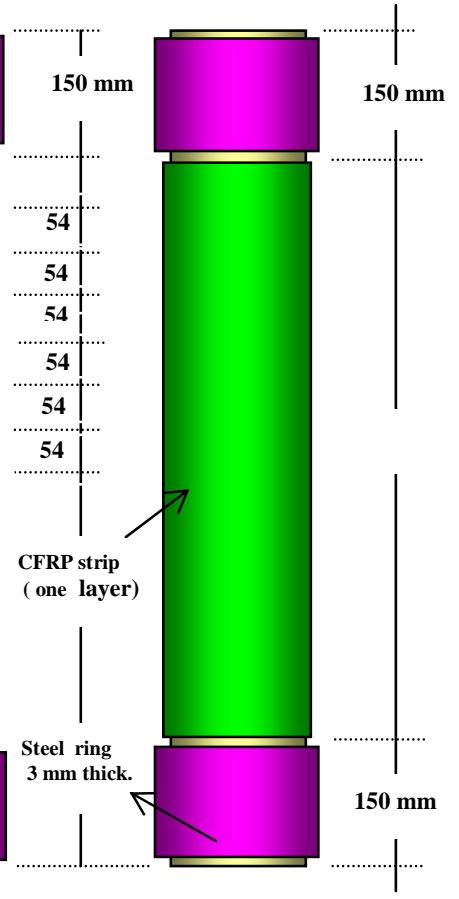

Column C.1-4

Fig. 2: Details and arrangements of bonded CFRP sheets for tested columns. 
The wrapping reinforcement was a CFRP sheet under a commercial name of Sika Wrap Hex-230C [4]. Such CFRP sheet is available in rolled sheet of $0.13 \mathrm{~mm}$ effective thickness and $300 \mathrm{~mm}$ width. The effective thickness gives the section of the fibers in each single ply. The ultimate strength and Young's modulus of such CFRP sheet are 3500 and $230000 \mathrm{~N} / \mathrm{mm}^{2}$, respectively.

Deformed bars (Steel 360/520) of $10 \mathrm{~mm}$ diameter were used for main internal reinforcement and plain bars (Steel 240/350) of $6 \mathrm{~mm}$ diameter were used for internal stirrups. Proof (yield) stress and tensile strength as well as Young's modulus are 412, 673 and $215000 \mathrm{~N} / \mathrm{mm}^{2}$ for $10 \mathrm{~mm}$ diameter bars, and 275, 395 and $196000 \mathrm{~N} / \mathrm{mm}^{2}$ for $6 \mathrm{~mm}$ diameter bars.

\section{Instrumentation}

To measure the strain of the wrapped CFRP sheet in the circumferential direction, three electrical strain gauges (one of each strip of the middle three strips in case of columns C.1-1, C.1-2, C.1-3 \& C.2-1, and at the middle zone of $100 \mathrm{~mm}$ apart in case of column C.1-4) of $10 \mathrm{~mm}$ gauge length were attached at the surface of the bonded CFRP sheets. Moreover, four displacement dial gauges were fixed vertically at different levels of the tested columns to measure both average and mid-height axial strains.

\section{ANALYSIS OF EXPERIMENTAL RESULTS}

A summary of the observed results for the different tested columns is presented in Table 2. Table 2 shows the obtained experimental results: cracking load $P_{c r}$; maximum load $\left(P_{\max }\right)$; maximum load of the strengthened column to that of the corresponding reference column $\left(P_{\max , s /} P_{\max , o}\right)$; maximum axial stress $\left(\mathrm{P}_{\max } / \mathrm{A}_{\mathrm{g}}\right)$; maximum and mean strains (the average of the three values measured in the middle third) induced in CFRP sheet at failure $\varepsilon_{f, \text { max }}, \varepsilon_{f, \text { mean }}$ (circumferential strain); maximum axial strain induced in the concrete $\varepsilon_{c, \max }$ (at mid-height) and the failure mode.

Table 2: Experimental results for tested columns.

\begin{tabular}{|c|c|c|c|c|c|c|c|c|}
\hline \multirow{2}{*}{$\begin{array}{l}\text { Column } \\
\text { No. }\end{array}$} & \multirow{2}{*}{$\begin{array}{r}\boldsymbol{P}_{\boldsymbol{c r}} \\
{[\mathrm{kN}]}\end{array}$} & \multirow{2}{*}{$\begin{array}{l}\boldsymbol{P}_{\text {max }} \\
{[\mathrm{kN}]}\end{array}$} & \multirow{2}{*}{$\begin{array}{c}\boldsymbol{P}_{\max } / \boldsymbol{A}_{g} \\
{[\mathrm{MPa}]}\end{array}$} & \multirow{2}{*}{$\begin{array}{c}P_{\max , s} / \\
P_{\max , o} \\
{[-]}\end{array}$} & \multicolumn{3}{|c|}{$\begin{array}{c}\text { Maximum Strains } \\
{[\mathrm{mm} / \mathrm{m}]}\end{array}$} & \multirow{2}{*}{$\begin{array}{c}\text { Failure } \\
\text { Mode }\end{array}$} \\
\hline & & & & & $\varepsilon_{\mathrm{c}, \max }$ & $\varepsilon_{\mathrm{f}, \max }$ & $\varepsilon_{\mathrm{f}, \text { mean }}$ & \\
\hline C.1-0 & 458 & 458 & 25.9 & 1.00 & 3.84 & --- & --- & F.M.1 \\
\hline C.1-1 & 590 & 649 & 36.2 & 1.42 & 5.77 & 9.11 & 8.10 & F.M.2 \\
\hline C.1-2 & 640 & 695 & 39.3 & 1.52 & 6.30 & 10.12 & 8.68 & F.M.2 \\
\hline C.1-3 & 780 & 826 & 46.7 & 1.80 & 8.50 & 6.81 & 6.62 & F.M.3 \\
\hline C.1-4 & 750 & 811 & 45.9 & 1.77 & 7.20 & 8.24 & 7.54 & F.M.2 \\
\hline C.2-0 & 510 & 520 & 29.4 & 1.00 & 4.41 & --- & --- & F.M.1 \\
\hline C.2-1 & 670 & 710 & 40.2 & 1.37 & 5.80 & 8.20 & 7.61 & F.M.2 \\
\hline
\end{tabular}

$A_{g}$ is gross cross-sectional area of column, F.M.1 is first failure mechanism, F.M.2 is second failure mechanism and F.M.3 is third failure mechanism. 


\section{Maximum Load and Efficiency of Strengthening Technique}

The strengthened columns provided with no internal stirrups C.1-1, C.1-2, C.1-3 \& C.1-4 showed an improvement in the load carrying capacity in comparison with the corresponding reference column C.1-0, particularly in case of column C.1-3 confined with two plies of CFRP sheets $\left(\rho_{f} \approx 3.33 \%\right.$ ) and column $C .1-4$ fully wrapped with one ply of CFRP sheets $\left(\rho_{f} \approx 3.47 \%\right.$ ), see Fig. 3. However, columns C.1-1 \& C.1-2 provided with lower volume of confining CFRP strips $\left(\rho_{f} \approx 1.67 \%\right.$ ) showed a higher strengthening efficiency, where the failure was occurred due to the rupture of the CFRP strips. In case of these two strengthened columns C.1-1 \& C.1-2 provided with the same amount of wrapped CFRP sheets $\left(\rho_{f} \approx 1.67 \%\right.$ ), the load carrying capacity enhanced as spacing between the CFRP strips decreased. The strengthened columns C.1-1 \& C.1-2 proved an improvement in the load carrying capacity amounted to 1.42 and 1.52 times that of the corresponding reference column C.1-O, respectively. For columns provided with internal stirrups, the strengthened column C.2-1 ( $\rho_{f} \approx 1.67 \%$ ) proved an improvement in the load carrying capacity amounted to 1.37 times that of the corresponding reference column C.2-O.

When considering the first cracking, the first crack initiated at a load level equal more or less to the maximum load in case of the reference columns C.1-O and C.2-O however, it initiated at a load level ranged from 0.91 to 0.94 times the maximum load in case of strengthened columns.

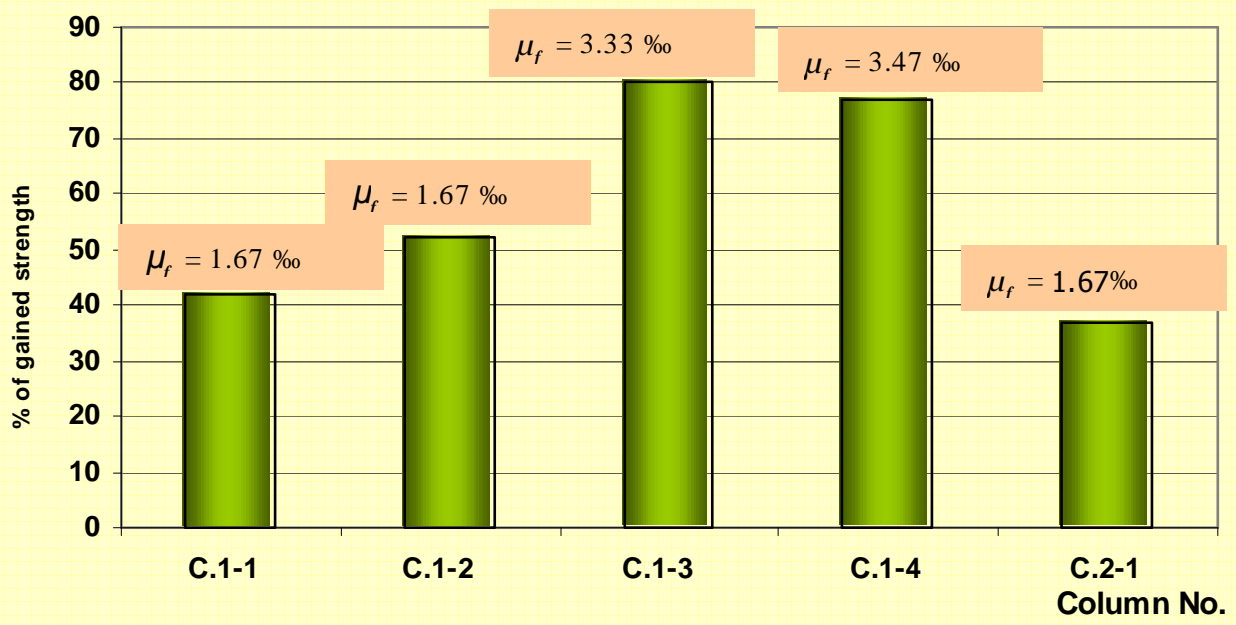

Fig. 3: Gain in strength for the different strengthened columns.

Throughout the obtained results concerning the load carrying capacity, it is worth to note that, for the same amount of wrapped CFRP sheets, the efficiency of the confining strengthening technique improved as the spacing between the wrapped CFRP strips decreased. Also, for the same spacing between the wrapped CFRP strips, the efficiency of the strengthening technique enhanced as the amount of wrapped CFRP sheets 
decreased. Hence, a question is raised; did the column C.1-2 $\left(P_{\max }=695 \mathrm{kN}\right)$ satisfy a strengthening efficiency more than columns $C .1-3\left(P_{\max }=826 \mathrm{kN}\right)$ and C.1-4 $\left(P_{\max }=\right.$ $811 \mathrm{kN})$ ?, the answer should be: of course yes, where Column C.1-2 provided with a strengthening ratio $\rho_{f}\left(=A_{f} / A_{c}\right)$ equal to $1.67 \%$ satisfied a gain in strength of $52 \%$ (a gain in strength of $31.1 \%$ per each $1.0 \%$ strengthening ratio), Column C.1-3 provided with $\rho_{f}$ equal to $3.33 \%$ satisfied a gain strength of $80 \%$ (a gain in strength of $24.0 \%$ per each $1.0 \%$ strengthening ratio) and Column C.1-4 provided with $\rho_{f}$ of $3.47 \%$ satisfied a gain strength of $77 \%$ (a gain in strength of $22.2 \%$ per each $1.0 \%$ strengthening ratio). From authors' point of view, this means that to achieve a higher possible efficiency for the applied confining strengthening technique, it is better to apply strips with minimum number of plies and consequently minimum spacing between these strips for the same amount of wrapped CFRP sheets to cover the maximum possible area of the column' surface area. What was occurred in case of column C.1-4 (one ply, $\rho_{f} \approx 3.47 \%$ ) when compared with column C.1-3 (two plies, $\rho_{f}$ $\approx 3.33 \%$ o) does not contradict with what we mentioned above. This exceptional result may be attributed to the premature failure mode occurred in case of column C.1-4. Such a premature failure mode occurred mainly due to a crack initiated at the upper end region (un-strengthened zone) and propagated towards the beginning of the strengthened zone causing a rupture of the wrapped CFRP sheet in that zone. Moreover, the effect of amount of internal stirrups on the efficiency of the confining strengthening technique showed a similar trend to that of the amount of wrapped CFRP sheets: the efficiency of the confining strengthening technique improved as the amount of internal stirrups decreased.

\section{Failure Behaviour}

Throughout the experimental tests carried out on the columns, three mechanisms of failure were observed. The first one was due to the inclined crack initiated at the middle third zone and propagated suddenly causing failure accompanied with a crushing of the concrete cover at that zone. This mechanism was observed in case of the reference columns C.1-O and C.2-O. The second one was due to both a rupture of one of CFRP strips located at the middle third accompanied with a delamination of concrete cover along the whole premiter of that strip and a complete concrete crushing at that zone simultaneously. A complete concrete crushing here means a separation (de-bonding) of the coarse aggregate from the sand-cement mortar at that zone. This mechanism was observed in case of columns strengthened with a number of CFRP strips of one ply C.1-1, C.1-2 and C.2-1, see Fig. 4. The third mechanism was due to a concrete crushing at the unconfined zones between CFRP strips. This mechanism was observed in case of column strengthened with a number of CFRP strips ( 5 strips) of two plies C.1-3. The failure mechanism of the strengthened column C.1-4 was similar to the second mechanism but the failure occurred at the upper first third instead of the middle third, see Fig. 4.

\section{Stress-Strain Behavior}

The measured strains in axial and circumferential directions were recorded at the different axial stress levels $\left(P_{\max } / A_{g}\right)$ for the different tested columns and plotted in Figs. 5 to 7. Throughout the axial stress-axial strain behavior for the different tested 


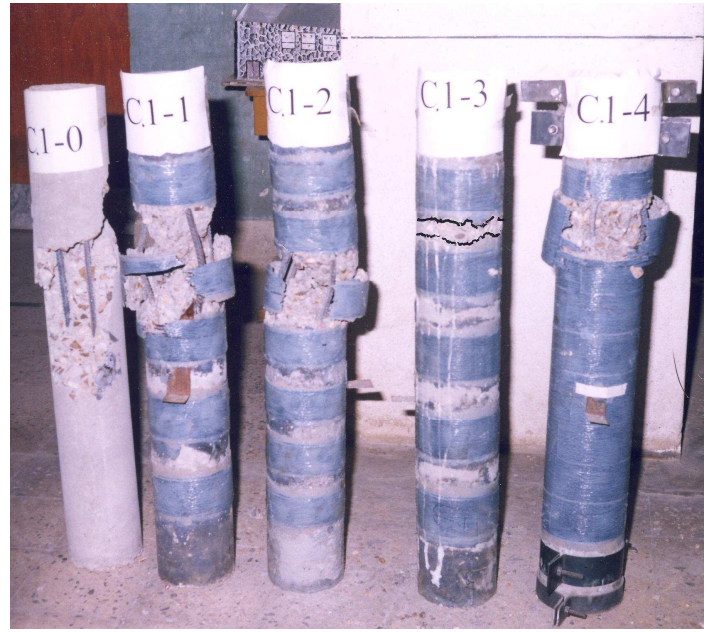

(a) Group C.1-

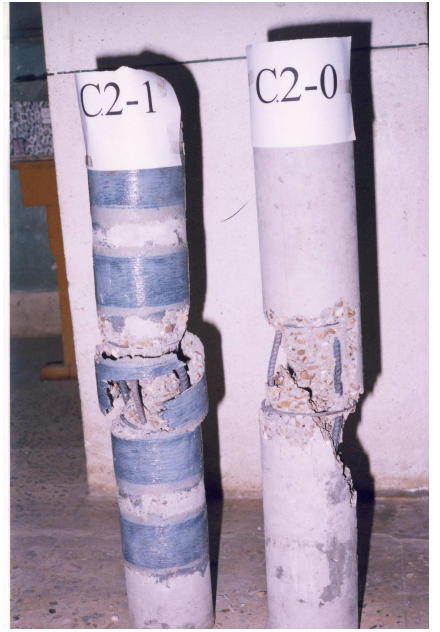

(b) Group C.2-

Fig. 4: Failure aspect of the different columns.

columns (Figs. 5 and 6), it is obvious that, the stress-strain relation of the strengthened columns was somewhat a linear one up to a level of loading about the maximum load of the corresponding reference columns in case of columns partially wrapped with one ply C.1-1, C.1-2 \& C.2-1 however, the relationship still linear up to a load level beyond the maximum load of the corresponding reference column in case of column partially wrapped with two plies $C .1-3$ and that fully wrapped C.1-4. Once the strengthened columns C.1-1, C.1-2 \& C.2-1 are loaded above the load carrying capacity of the corresponding reference columns the stiffness decreased, particularly at a higher loading levels. On the other side, in case of columns C.1-3 \& C.1-4 the stiffness starts to decrease reasonably at a load level about 0.90 times the maximum load. At the same axial stress level, the strengthened columns showed a smaller axial strain in comparison to the corresponding reference columns (without strengthening), particularly in case of both fully wrapped column C.1-4 and that confined with two plies of CFRP strips C.1-3. However, at the maximum load level, the strengthened columns showed a higher axial strain in comparison to the corresponding reference columns, particularly in case of column confined with two plies C.1-3 that failed due to a concrete crushing at the unconfined zones between CFRP strips. On the other hand, for columns strengthened with the same amount of wrapped reinforcement C.1-1 \& C.1-2, when considering the free (clear) spacing between the wrapped CFRP strips $s$, the strengthened column provided with a smaller free spacing C.1-2 showed approximately the same stress-strain behavior at a lower stress levels, however a reasonable influence was observed at a higher stress levels: the axial strain increased as the free spacing increased, but the maximum axial strain increased as the free spacing increased decreased. Moreover, when considering the amount of the internal stirrups, the strengthened columns C.1-1 \& C.2-1 showed an enhancement in the stiffness (decreasing the axial strain) in comparison with the corresponding reference columns C.1-O \& C.2-0, particularly in case of columns provided with no internal stirrups. 


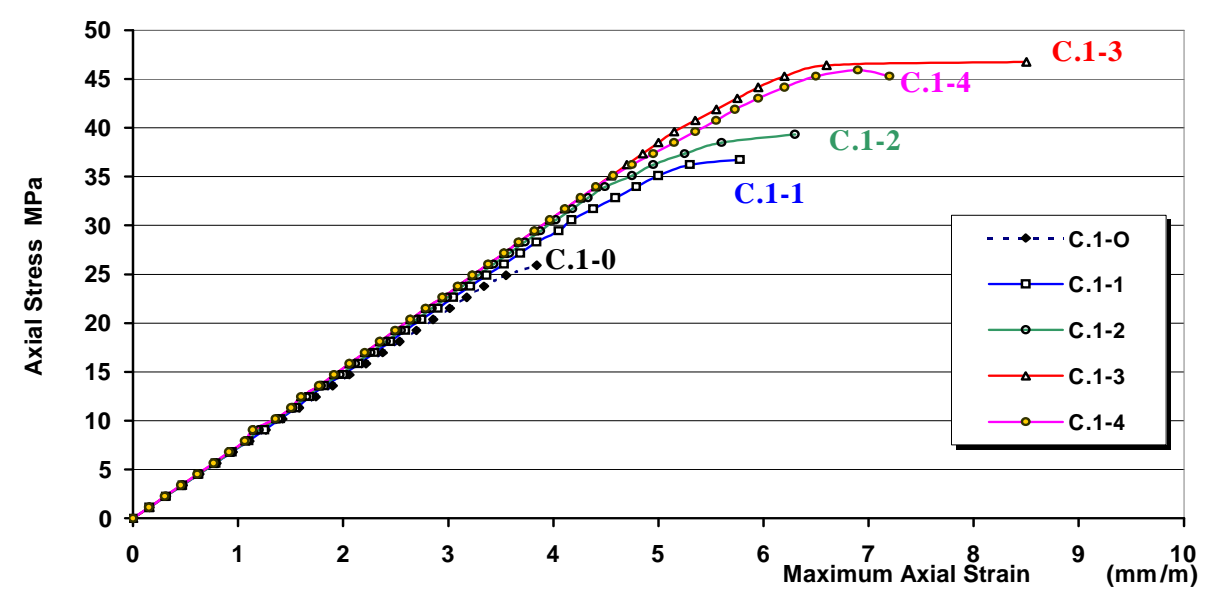

Fig. 5: Axial stress-axial strain diagrams for the different columns of group C.1-.

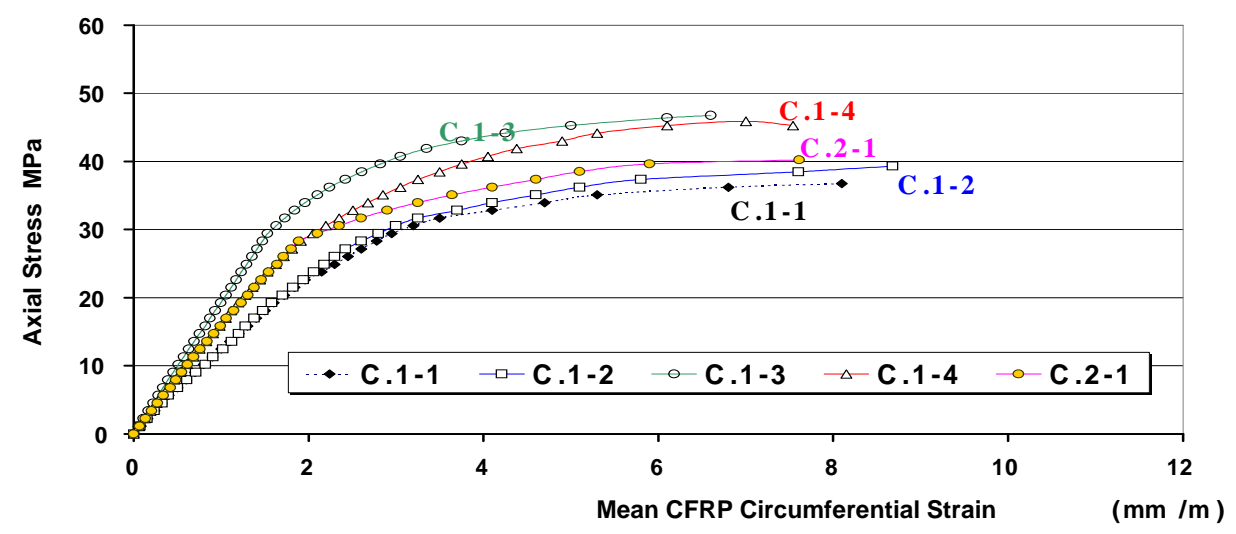

Fig. 6: Axial stress-axial strain diagrams for the different columns of group C.2-.

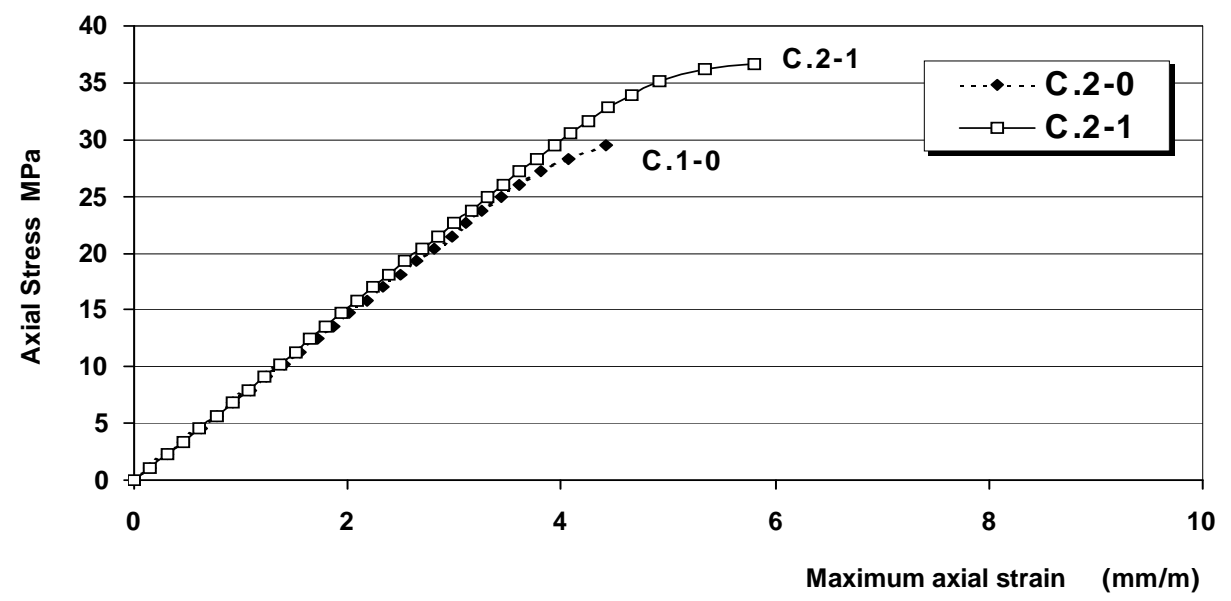

Fig. 7: Axial stress-mean CFRP circumferential strain diagrams of tested columns. 
The axial stress-CFRP strain (circumferential strain) behavior for the different strengthened columns are shown in Fig. 7: figure 7 shows axial stress-mean CFRP strain (the average of the three values measured in middle third of the column) curves. From Fig. 7 it emerged that, the different strengthened columns showed a higher possible exploitation to the bonded CFRP sheet but column C.1-3 confined with strips of two plies which showed lower exploitation, where a rupture of the confined CFRP strips was observed for the different strengthened columns but column C.1-3 that failed due to a crushing of concrete at the free spacing zones. It is worth to note that although the strengthened column C.1-4 failed due to a rupture of the bonded CFRP sheet, the measured maximum circumferential CFRP strain showed a smaller value in comparison with those failed in a similar manner C.1-1, C.1-2 \& C.2-1. This is attributed to the fact that the rupture of the bonded CFRP sheet occurred at the end region in case of column C.1-4 but the rupture occurred in one of the strips located at the middle third region in case of columns C.1-1, C.1-2\& C.2-1, see Fig. 7 and Table 2.

Through Fig. 7 and Table 2, it is obvious that the strengthened columns failed due to the rupture of the CFRP strips showed a higher maximum circumferential strain in comparison with those failed due to concrete crushing at the free zones (unconfined zones). The circumferential CFRP strain gives us an indication about the degree of exploitation of the used wrapped reinforcement. By other words, the efficiency of the used strengthening technique is expressed by the ratio of the induced circumferential CFRP strain to the ultimate strain of the used CFRP sheets. As a consequence, it emerged that columns C.1-2, C.1-1 and C.2-1 satisfied higher strengthening efficiency in comparison with the other strengthened columns. Moreover, it is important to mention that, although a rupture of CFRP strips was occurred in case of columns C.11, C.1-2 and C.2-1, the induced maximum strain in that strips hadn't reached the expected ultimate value of the CFRP strain (about $15 \mathrm{~mm} / \mathrm{m}$ ). This is attributed to the fact that the CFRP cut-off hadn't occurred at the location of the strain gauges amounted to measure the circumferential strain induced in the CFRP strips as well as a stress concentration occurred at a region where the major crack formed.

\section{Structural Ductility}

Ductility is a desirable feature of any structural design as a safety factor against unpredicted overloading. In general, the structural ductility of an element exposed to axial load may be given by the ductility factor which by its turn can be expressed by the total vertical contraction at failure $\left(\delta_{f}\right)$ to that corresponding to the first yielding of internal main reinforcement $\left(\delta_{y}\right)$. The total vertical contraction occurred in the column at failure $\left(\delta_{f}\right)$ expresses the contraction corresponding to the apparent failure, e.g. rupture of CFRP strips or concrete crushing or when strength reduces to $85 \%$ of the maximum load. As a matter of fact, the different tested columns failed suddenly at the maximum load level but columns C.1-3 (provided with two plies of CFRP sheet) and C.1-4 (fully wrapped), which show a considerable deformation after reaching the maximum load (attaining the maximum load). The total vertical contraction corresponding to the first yielding of internal main reinforcement $\left(\delta_{y}\right)$ was more or less $2.66 \mathrm{~mm}$ for the different tested columns. However the total vertical contraction 
occurred in the different columns corresponding to the apparent failure $\left(\delta_{f}\right)$ were 2.69, 4.04, 4.41, 5.95, 5.04, 3.09 and $4.06 \mathrm{~mm}$ for columns C.1-0, C.1-1, C.1-2, C.1-3, C.1$4, C .2-0$ and C.2-1 respectively. Consequently, the ductility factor was $1.01,1.52,1.66$, 2.24, 1.90, 1.16 and 1.53 for columns C.1-0, C.1-1, C.1-2, C.1-3, C.1-4, C.2-0 and C.21 respectively. As a result, it is worth to note that the structural ductility of column improved considerably when confined with CFRP sheets, particularly in case of columns confined with greater amount of CFRP sheets C.1-3 \& C.1-4. Moreover, for columns confined with the same amount of CFRP sheets C.1-1\& C.1-2, the smaller the free spacing between CFRP strips the higher the structural ductility. Also, the ductility factor can be expressed by the ratio of total absorbed energy per unit volume at failure $\left(E_{f}\right)$ to that corresponding to the first yielding of internal main reinforcement $\left(E_{y}\right)$. The total absorbed energy per unit volume can be measured by the area under the axial stress-axial strain curves. Consequently, and through Figs. $\mathbf{5}$ and $\mathbf{6}$, it is obvious that the structural ductility of column improved considerably when confined with CFRP sheets, particularly in case of columns confined with greater amount of CFRP sheets C.1-3 \& C.1-4. Moreover, the resistance of a structural element exposed to axial load to the dynamic loading may be expressed by the total absorbed energy per unit volume in terms of the area under the axial stress-axial strain curves. As a result, the confined columns showed a higher resistance to the dynamic loading in comparison to the unstrengthened columns, particularly in case of columns confined with greater amount of CFRP sheets C.1-3\& C.1-4, see Fig. 6.

\section{MATHEMATICAL MODELLING}

\section{Load Carrying Capacity of R.C. Strengthened Columns}

The obtained experimental results showed that the load carrying capacity of R.C. columns confined with wrapped CFRP sheet improved considerably in comparison with the corresponding reference columns. So that the load carrying capacity of strengthened columns is affected by the confined concrete strength $f_{c c}$ which by its turn is affected by the degree of confinement. As a result, and similar to the unstrengthened R.C. columns, the load carrying capacity of strengthened columns $P_{\max , s}$ can be obtained according to Eq.(1). Consequently, to predict the load carrying capacity of R.C. columns strengthened externally by means of wrapped CFRP sheets, it should predict both the confining pressure $f_{r}$ due to externally wrapped sheets and the axial strain corresponding to the failure $\varepsilon_{\mathrm{c}, \max }$.

$$
P_{\max , s}=f_{c c} A_{c}+f_{s} A_{s}
$$

in which $A_{c}$ is area of concrete cross-section, $f_{c c}$ is confined cylinder concrete strength, $A_{s}$ is area of longitudinal reinforcement and $f_{s}$ is the stress of longitudinal reinforcement corresponding to the maximum load of strengthened column $P_{\max , s}$.

\section{Equivalent Confinement Pressure}

For a circular short column confined with a fully wrapped CFRP sheet, the lateral confining pressure $f_{r}$ exerted on the concrete core is assumed a uniform one and calculated according to Eq.(2) by assuming uniform tension in the CFRP sheet, see Fig. 8. 


$$
f_{r}=\frac{2 f_{f} n t_{f}}{D}=0.5 \rho_{f} f_{f}
$$

where, $\quad \rho_{f, F}=\frac{A_{f}}{A_{c}}=\frac{\pi D n t_{f}}{\pi D^{2} / 4}=\frac{4 n t_{f}}{D}$

in which $f_{f}$ is the stress in the CFRP sheet, $\rho_{f, F}$ is the ratio of the volume of wrapped reinforcement $A_{f}$ to the volume of confined concrete core $A_{c}$ per unit length for a fully wrapped columns, $n$ is the number of CFRP plies, $t_{f}$ is the thickness of the CFRP sheet, and $D$ is the diameter of the circular column.
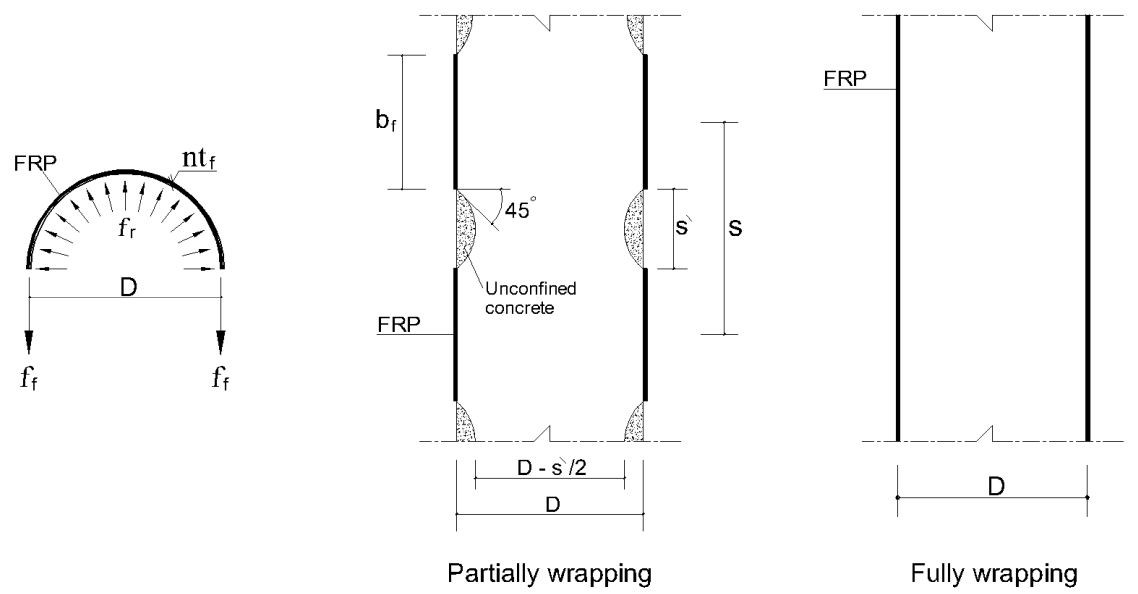

Fig. 8: Confining pressure exerted by wrapping FRP sheet on a circular column [5].

If the concrete is partly wrapped, less efficiency is obtained as both confined and unconfined zones existed, see Fig. 8. In this case, the effective lateral confining pressure is obtained according to Eq. (3) by introducing a confinement effectiveness coefficient $k_{e} \leq 1.0$. The effectiveness coefficient is obtained by considering that the transverse pressure from the confining system is only effective on that part of the concrete where the confining pressure has fully developed due to arching action, which is assumed as a parabola with an initial slope of $45^{\circ}$ [5], see Fig. 8. As a result, at the midway between two successive wrapped CFRP strips, the area of effectively confined concrete core $A_{e}$ is obtained through Eq. (4). Consequently, the confinement effectiveness coefficient $k_{e}$ is obtained by considering the ratio $\left(A_{e} / A_{c}\right)$, where $A_{c}$ is the difference between the gross cross-sectional area $A_{g}$ and the area of longitudinal steel $A_{s}:\left(A_{c}=A_{g}-A_{s}\right)$.

$$
\begin{aligned}
& f_{r}=0.5 k_{e} \rho_{f} f_{f} \\
& k_{e}=\frac{A_{e}}{A_{c}}=\frac{\frac{\Pi}{4}\left(D-\frac{s^{\prime}}{2}\right)^{2}}{A_{g}-A_{s}}=\frac{\left(1-\frac{s^{\prime}}{2 D}\right)^{2}}{1-\rho_{s g}}
\end{aligned}
$$


where, $\quad \rho_{f}=\frac{A_{f} \pi D}{\left(\pi D^{2} / 4\right) \times s}=\frac{4 b_{f} n t_{f}}{D s}$

in which $b_{f}$ is the width of the CFRP strips, $s$ is spacing between center to center of the CFRP strips ( $s=b_{f}$ in case of fully wrapping), $s^{\prime}\left(=s-b_{f}\right)$ is the clear spacing between two successive wrapped CFRP strips, $\rho_{s g}$ is the reinforcement ratio of the longitudinal steel reinforcement with respect to the gross cross-sectional area $\left(=A_{s} / A_{g}\right)$.

\section{Effective CFRP Strain and Maximum Effective Confinement Pressure}

According to the experimental results obtained from the different researches on columns confined with FRP reinforcement $[3,6,7]$, the mean effective FRP strain at failure $\varepsilon_{f, e f f}$ is lower than the ultimate strain of the FRP confining reinforcement $\varepsilon_{f, u}$. Based on the experimental results of R.C. columns confined with FRP reinforcement [3, 6], Matthys [3] suggests a coefficient $\eta\left(=\varepsilon_{f, e f f} / \varepsilon_{f, u}\right)$, see Eq.(6). So that the maximum effective confinement pressure $f_{r, e}$ is obtained according to Eq. (5).

$$
\begin{aligned}
f_{r, e} & =0.5 k_{e} \rho_{f}\left(\eta f_{f, u}\right) \\
\eta & =0.105\left(k_{e} K_{\text {conf }}\right)^{0.266} \\
K_{\text {conf }} & =0.5 \rho_{f} E_{f}
\end{aligned}
$$

in which $E_{f}$ is the elastic modulus of wrapping CFRP sheet in N/mm²

Through the predicted effective CFRP failure strain obtained according to the expression suggested by Matthys [3] (see Eq. (6)) it emerged that, the effective CFRP failure strain increases due to the increase of both confinement effectiveness coefficient $\left(k_{e}\right)$ and the stiffness of bonded CFRP sheet in terms of $K_{\text {conf }}\left(=0.5 \rho_{f} E_{f}\right)$. The predicted results concerning the effective CFRP failure strain obtained according to the expression suggested by Matthys contradict with the experimental results obtained in this work results which attest that such value $\left(f_{f, e f f}\right)$ is directly proportion with the confinement effectiveness coefficient $\left(k_{e}\right)$ and inversely proportion with the stiffness of bonded CFRP sheet in terms of $K_{\text {conf }}$, see Fig. 9. Such a contradiction between the predicted and actual (experimental) results is attributed to the fact that Matthys overlooked the results corresponding the values of $\left(k_{e} K_{\text {conf }}\right)$ smaller than 500 $\mathrm{N} / \mathrm{mm}^{2}$ when performing the suggested expression, and as a matter of fact, in case of smaller or medium strengthening ratio $\left(\rho_{f}\right)$ the value of $\left(k_{e} K_{c o n f}\right)$ is usually equal to or smaller than $500 \mathrm{~N} / \mathrm{mm}^{2}$.

As the effective CFRP failure strain depends on various aspects and parameters, for which the influence and interaction are difficult to be quantified analytically, the author proposed a modified relationship for the ratio of the effective CFRP failure strain to the ultimate CFRP strain $\eta_{\text {mod }}\left(=\varepsilon_{f, e f f} / \varepsilon_{f, u}\right)$. The modified expression is based on performing a curve fitting which by its turn based on the $\left(\varepsilon_{f, e f f} / \varepsilon_{f, u}\right)$ and $\left(\sqrt{ } k_{e} / K_{\text {conf }}\right)$ data points, see Fig. 10 and Eq.(8). The value of the effective CFRP failure strain is the average of the three values measured through the strain gauges amounted onto the bonded CFRP sheet and located at the middle part of the tested strengthened columns. 
So that the maximum effective confinement pressure $f_{r, e}$ can be obtained according to Eq. (5) by replacing $\eta$ obtained according Eq.(6) with $\eta_{\text {mod }}$ obtained according Eq. (8).

$$
\eta_{\mathrm{mod}}=1.8637\left(\frac{\sqrt{k_{e}}}{K_{\text {conf }}}\right)^{0.225}
$$

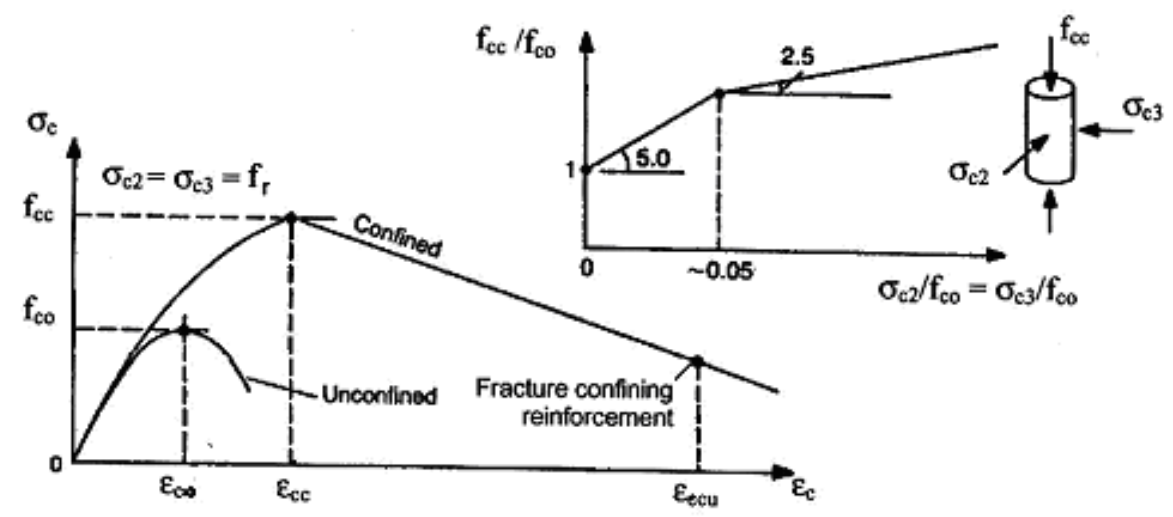

Fig. 9: Model for confined concrete (constant confining action) [8].

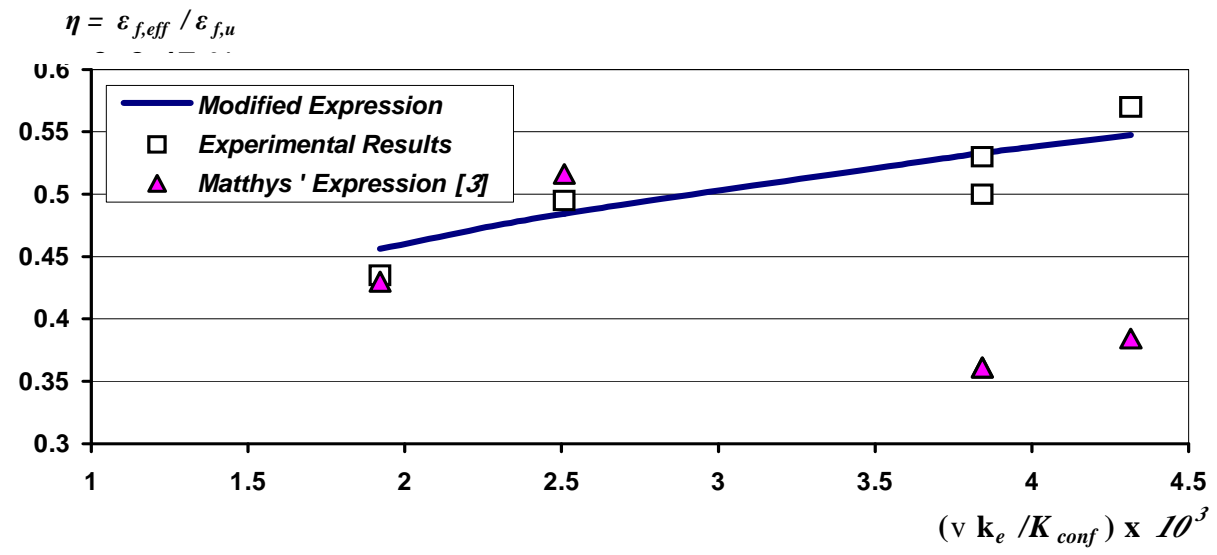

Fig. 10: Predicted and experimental values of the coefficient $\eta\left(=\varepsilon_{f, e f f} / \varepsilon_{f, u}\right)$.

\section{Confined Concrete Strength and Axial Strain}

Various models for confinement of concrete have been developed, primarily for steel wrapping reinforcement $[8,9]$. These models basically provide an equivalent uniaxial stress-strain relationship for confined concrete, see Fig. 9. These models assume a constant confining pressure, and in reality confinement action increases as the concrete expands. For steel transverse reinforcement, the assumption of the constant confining 
pressure is somewhat realistic when the stress level is in yielding stage. On the contrary, FRP reinforcement behaves linear elastically up to failure and the inward radial pressure (confining pressure) increases as the concrete expands laterally.

Regardless of the complete stress-strain response of the FRP reinforcement, on the basis of both models assuming a constant confining pressure $[8,9]$ and the model of FRP confined concrete suggested by Saadatmanesh et al [2], both the confined concrete strength $f_{c c}$ and the corresponding axial strain $\varepsilon_{c c}$ were derived directly from the maximum effective confining pressure $f_{r, e}$ by Spoelstra and Monti [10], Eq.(9) and Eq.(10). The maximum effective confining pressure $f_{r, e}$ corresponds the effective CFRP strain $\varepsilon_{f, e f f}$ which can be predicted by the expression suggested by the authors, see Eq.(5) and Eq.(8).

$$
\begin{aligned}
& f_{c c}=\alpha_{1} \alpha_{2} f_{c o} \\
& \varepsilon_{c c}=\left[1.0+5.0\left(\alpha_{1} \alpha_{2}-1.0\right)\right] \varepsilon_{c o}
\end{aligned}
$$

with,

$$
\begin{aligned}
& \alpha_{1}=2.254 \sqrt{1.0+7.94 \frac{f_{r, e}}{f_{c o}}}-2.0 \frac{f_{r, e}}{f_{c o}}-1.254 \quad \text { (for circular section) } \\
& \alpha_{2}=1.0 \quad \text { (for circular section) }
\end{aligned}
$$

in which $f_{c o}$ is unconfined concrete strength and $\varepsilon_{c o}(=2 \mathrm{~mm} / \mathrm{m})$ is the compressive strain corresponding to $f_{c o}$.

\section{Analytical Verification}

The predicted load carrying capacity of the tested columns $\left(P_{p r}\right)$ according to Eq. (1) and based on Eq. (5) suggested to predict confined concrete strength which by its turn based on either the modified expression suggested by the authors (see Eq.(8) and Table 3) or the expression suggested by Matthys [3] (see Eq.(6) and Table 4). The predicted values concerning the predicted load carrying capacity of the tested columns $P_{p r}\left(P_{p r l}\right.$ based on the expression suggested by the author and $P_{p r 2}$ based on the expression suggested by Matthys) were calculated and reported in Tables 4 \& 5 together with the corresponding results obtained experimentally for the different tested columns. Also, both effective circumferential CFRP strain and the maximum axial strain were calculated based on both the expression suggested by the authors (see Eqs. (8), and (10)) and that suggested by Matthys (see Eqs.(6) and (10)), and compared with the corresponding experimental results, see Tables $\mathbf{3} \& \mathbf{4}$.

It is worth to note that, when calculating the predicted results for columns C.2-0 and C.2-1, the internal stirrups are considered as externally confined reinforcement of effective circumferential strain equal to the yield strain of the used steel (steel 240/350).

Throughout Fig. 11 and Tables $3 \&$ 4, it is obvious that the calculated results according to the proposed model concerning the load carrying capacity of the strengthened columns achieved a considerable approach to the actual values 
Table 3: Experimental and Predicted (based on modified expression) results.

\begin{tabular}{|c|c|c|c|c|c|c|c|c|c|c|}
\hline \multirow{2}{*}{$\begin{array}{c}\text { Column } \\
\text { No. }\end{array}$} & \multicolumn{3}{|c|}{ Experimental Results } & \multicolumn{7}{|c|}{ Predicted Results } \\
\hline & $\begin{array}{l}\mathbf{P}_{\max } \\
\mathbf{K N}\end{array}$ & $\begin{array}{l}\varepsilon_{\mathrm{c}, \mathbf{e x p}} \\
\mathrm{mm} / \mathrm{m}\end{array}$ & $\begin{array}{c}\varepsilon_{\mathrm{f}, \mathrm{exp}} \\
\mathrm{m} / \mathbf{m}\end{array}$ & $\begin{array}{l}\mathbf{k}_{\mathrm{e}} \\
-\%- \\
\end{array}$ & $\begin{array}{l}\eta_{\text {mod }} \\
-/-\end{array}$ & $\begin{array}{c}f_{r, e} \\
\mathbf{M P a}\end{array}$ & $\begin{array}{c}f_{c c} \\
\mathbf{M P a}\end{array}$ & $\begin{array}{l}\mathbf{P}_{\text {pr1 }} \\
\text { KN }\end{array}$ & $\begin{array}{c}\varepsilon_{\mathbf{c}, \mathrm{pr} 1} \\
\mathrm{~mm} / \mathbf{m}\end{array}$ & $\begin{array}{r}\varepsilon_{\mathrm{f}, \mathrm{pr}} \\
\mathrm{mm} / \mathrm{m}\end{array}$ \\
\hline C.1-0 & 458 & 3.84 & --- & --- & --- & 0 & 24.20 & 479.6 & 2.00 & --- \\
\hline C.1-1 & 649 & 5.77 & 8.10 & 0.5425 & 0.5332 & 0.8438 & 30.31 & 639.6 & 4.17 & 8.12 \\
\hline C.1-2 & 695 & 6.30 & 8.68 & 0.6846 & 0.5474 & 1.0932 & 31.77 & 664.4 & 4.76 & 8.33 \\
\hline C.1-3 & 826 & 8.50 & 6.62 & 0.5425 & 0.4562 & 1.4440 & 36.31 & 743.2 & 5.25 & 6.94 \\
\hline C.1-4 & 811 & 7.21 & 7.54 & 1.0000 & 0.4844 & 2.9392 & 40.23 & 811.2 & 8.62 & 7.37 \\
\hline C.2-0 & 520 & 4.41 & --- & 0.3117 & 1.0000 & 0.2014 & 25.77 & 523.5 & 2.56 & --- \\
\hline C.2-1 & 710 & 5.80 & 7.61 & 0.5425 & 0.5332 & 1.0452 & 30.98 & 650.7 & 4.70 & 8.12 \\
\hline
\end{tabular}

Table 4: Experimental and Predicted (based on Matthys' expression) results.

\begin{tabular}{|c|c|c|c|c|c|c|c|c|c|c|}
\hline \multirow{2}{*}{$\begin{array}{c}\text { Column } \\
\text { No. }\end{array}$} & \multicolumn{3}{|c|}{ Experimental Results } & \multicolumn{7}{|c|}{ Predicted Results } \\
\hline & $\begin{array}{l}\mathbf{P}_{\max } \\
\mathbf{K N} \\
\end{array}$ & $\begin{array}{l}\varepsilon_{\mathrm{c}, \mathbf{e x p}} \\
\mathrm{mm} / \mathrm{m}\end{array}$ & $\begin{array}{r}\varepsilon_{\mathrm{f}, \mathrm{exp}} \\
\mathrm{mm} / \mathrm{m}\end{array}$ & $\begin{array}{l}\mathbf{k}_{\mathbf{e}} \\
-/- \\
\end{array}$ & $\begin{array}{c}\boldsymbol{\eta} \\
-/ \\
\end{array}$ & $\begin{array}{c}f_{r, e} \\
\text { MPa }\end{array}$ & $\begin{array}{c}f_{c c} \\
\mathbf{M P a}\end{array}$ & $\begin{array}{l}\mathbf{P}_{\text {pr2 }} \\
\mathbf{K N} \\
\end{array}$ & $\begin{array}{r}\varepsilon_{\mathrm{c}, \mathrm{pr}} \\
\mathrm{mm} / \mathbf{m}\end{array}$ & $\begin{array}{r}\varepsilon_{\mathrm{f}, \mathrm{p} \mathbf{2}} \\
\mathrm{mm} / \mathbf{m}\end{array}$ \\
\hline C.1-0 & 458 & 3.84 & --- & --- & --- & 0 & 24.20 & 479.6 & 2.00 & --- \\
\hline C.1-1 & 649 & 5.77 & 8.10 & 0.5425 & 0.3612 & 0.5716 & 28.66 & 601.9 & 3.51 & 5.50 \\
\hline C.1-2 & 695 & 6.30 & 8.68 & 0.6846 & 0.3842 & 0.7674 & 29.86 & 631.3 & 3.99 & 5.85 \\
\hline C.1-3 & 826 & 8.50 & 6.62 & 0.5425 & 0.4343 & 1.3747 & 35.92 & 736.6 & 5.111 & 6.61 \\
\hline C.1-4 & 811 & 7.21 & 7.54 & 1.0000 & 0.5164 & 3.1330 & 41.06 & 825.8 & 8.97 & 7.86 \\
\hline C.2-0 & 520 & 4.41 & --- & 0.3117 & 1.0000 & 0.2014 & 25.77 & 523.5 & 2.56 & --- \\
\hline C.2-1 & 710 & 5.80 & 7.61 & 0.5425 & 0.3612 & 0.7730 & 29.38 & 623.0 & 4.04 & 5.50 \\
\hline
\end{tabular}

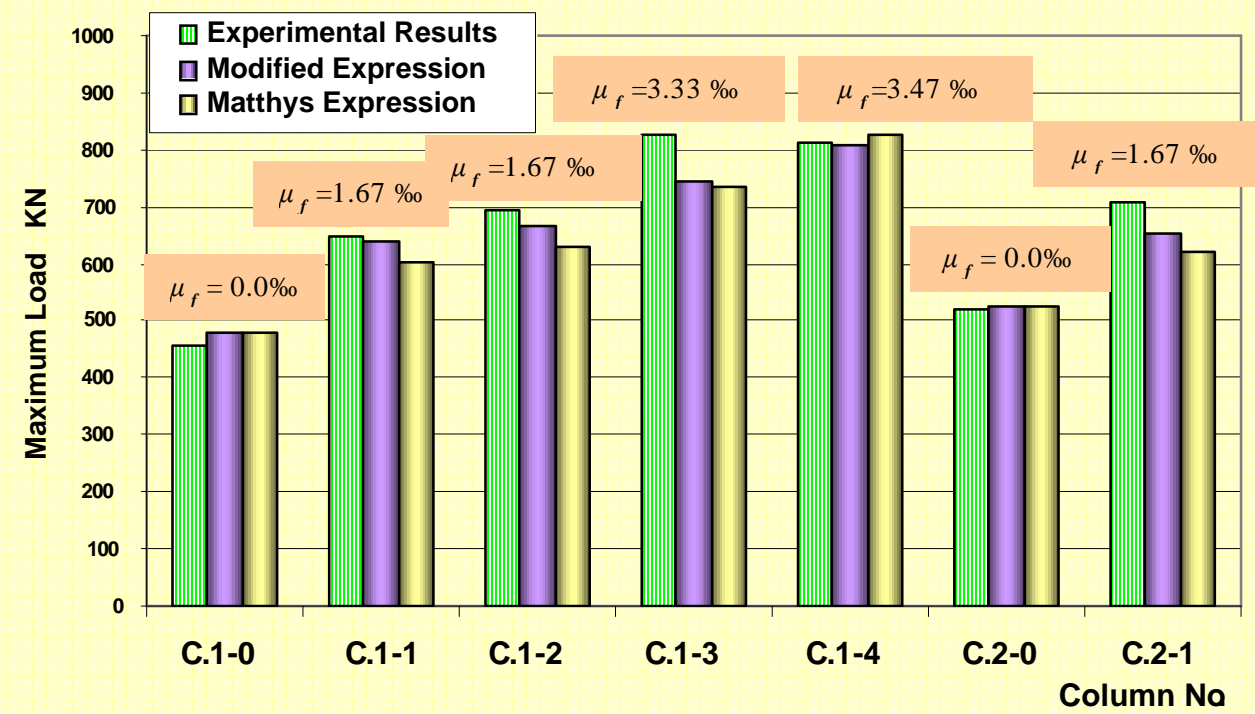

Fig. 11: Predicted maximum load in comparison with that obtained experimentally. 
(experimental results) particularly, when the expression suggested by the author to predict the effective CFRP failure strain is used. The ratio of the predicted maximum load of the strengthened column to that obtained experimentally $\left(P_{p r}, P_{e x p}\right)$ ranged between 0.90 and 0.99 when the expression suggested by the author was applied while it ranged between 0.87 and 1.02 when applying the expression suggested by Matthys. Moreover, on overlooking the results of the unstrengthened columns (C.1-0 \& C.2-0), the predicted values concerning both the effective circumferential CFRP strain and the maximum axial strain showed somewhat a considerable approach to the obtained experimental results particularly, when the expression suggested by the author to predict the effective CFRP failure strain is used, see Tables $\mathbf{3} \& \mathbf{4}$ and Figs. $12 \& \mathbf{1 3}$.

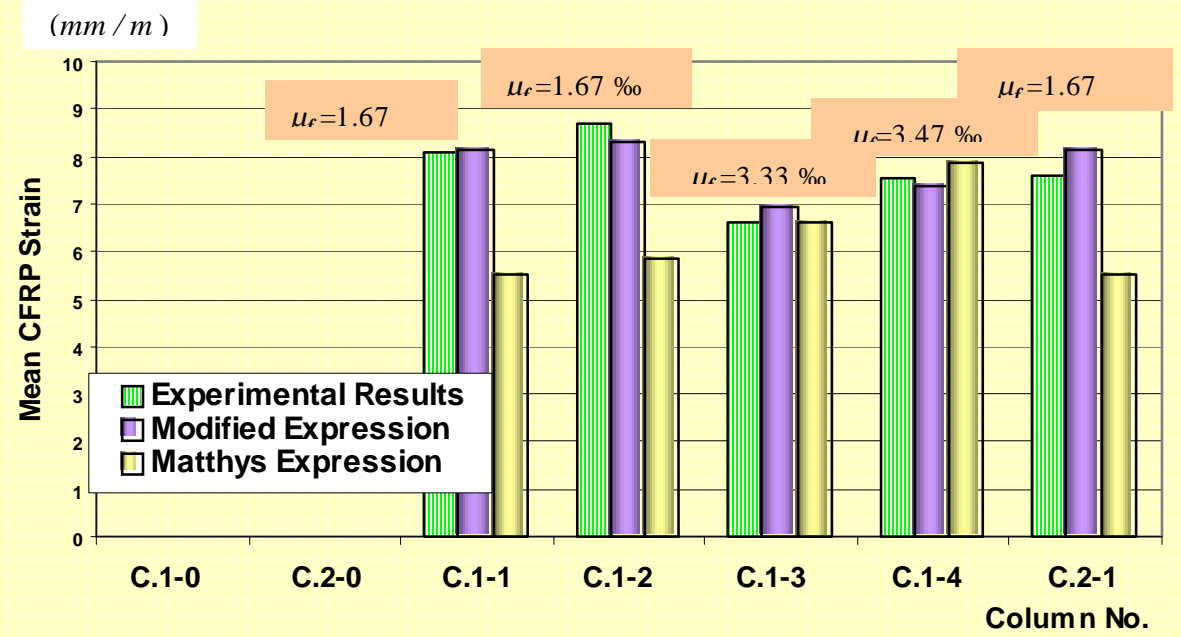

Fig. 12: Predicted and experimental mid-height axial concrete strain.

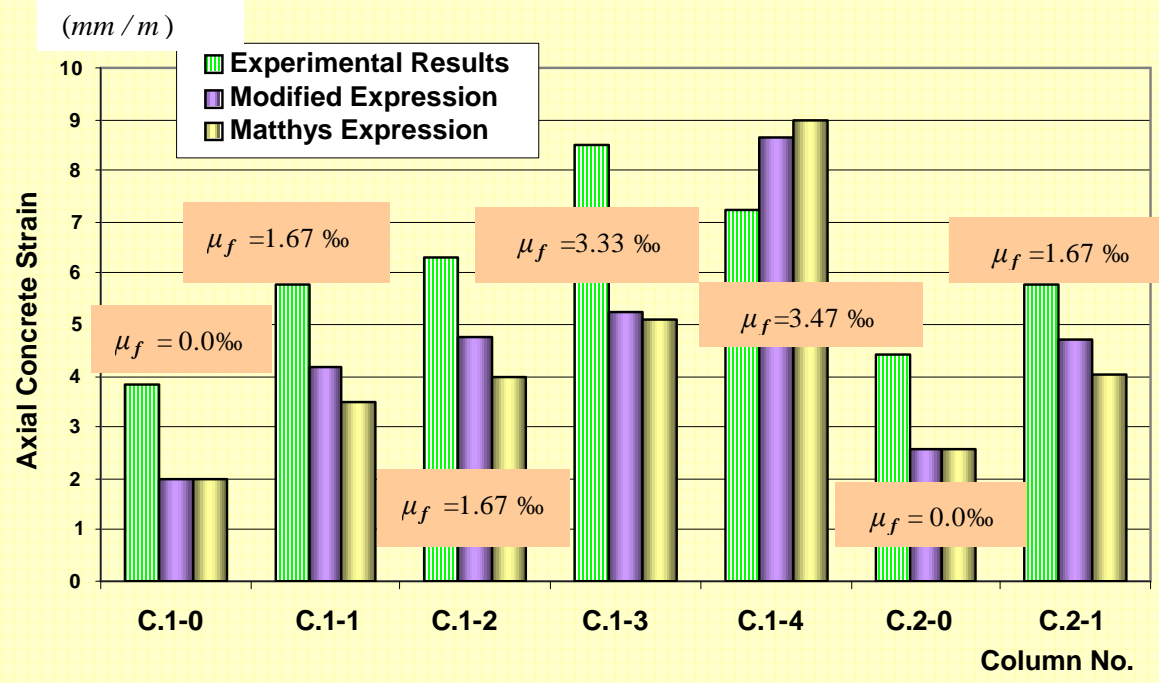

Fig. 13: Predicted and experimental mean circumferential CFRP strain. 


\section{CONCLUSIONS}

Based on the conducted experimental tests on wrapped circular R.C. columns and the performed analytical verifications, the following conclusions may be drawn:

- Confinement of circular columns by means of CFRP wrapping sheet is an efficient technique to improve the strength of these columns, particularly in case of fully wrapping or/and higher strengthening ratio. On the other hand, the efficiency of the used strengthening technique improved as strengthening ratio or/and clear spacing between the wrapped CFRP strips (unstrengthened zone) or/and the amount of internal lateral reinforcement (stirrups) decreased. Consequently, to achieve a higher possible efficiency for the applied confining strengthening technique of a certain strengthening ratio, it is better to apply strips with minimum possible number of plies and consequently minimum spacing between these strips to cover the optimum area of the column' surface area.

- For the same configuration of the used strengthening technique (the same width of CFRP strips and the same free spacing between these strips), the failure mode of the strengthened columns changed from the rupture of CFRP strips to the concrete crushing in the free zone (un-strengthened zone) as the strengthening ratio increased (increasing the number of CFRP plies)

- Confinement of circular columns by means of CFRP wrapping CFRP sheet is an efficient technique to improve the ductility of R.C. circular columns. Moreover, the used wrapping technique improved the ability of the columns to resist the dynamic loading in terms of the absorbed energy per unit volume (area under axial stressaxial strain curve), particularly in case of fully wrapping or/and higher strengthening ratio.

- Confinement of circular columns with CFRP wrapping CFRP sheet provides a considerable safety factor against the brittle failure, where the first crack occurred at a load level of about $91 \%$ to $94 \%$ of the maximum load in case of strengthened columns however, the first crack occurred at about the maximum load level in case of unstrengthened columns, particularly in case of columns provided with smaller amount of internal lateral reinforcement (stirrups).

- The model by Spoeltra and Monti [10] was found to be versatile enough to predict the stress-strain behavior of FRP confined concrete accurately under different conditions. Based on this model, more practical engineering models for the maximum strength and ultimate strain of FRP confined columns is proposed.

- On the basis of the obtained experimental results the author suggested a modified expression to predict the effective circumferential strain induced in the externally wrapped reinforcement at failure. Such an effective circumferential strain is used to predict the confinement pressure (lateral stress), which by its turn is used to predict the confined concrete strength and consequently the load carrying capacity of the strengthened columns.

- The predicted results concerning the load carrying capacity of R.C. columns strengthened with wrapping CFRP sheets obtained according to the proposed modified mathematical model showed a considerable approach to the results obtained experimentally, particularly when the expression suggested by the authors 
to predict the effective circumferential strain induced in the externally wrapped reinforcement is used.

- The predicted axial strain and mean circumferential strain of the CFRP sheet at failure showed a considerable approach to the obtained experimental results, particularly when the expression suggested by the author is applied.

\section{REFERENCES}

[1] Nanni A. (1993); Fiber-Reinforced-Plastic (FRP) Reinforcement for Concrete Structures: Properties and Applications, Developments in Civil Engineering, Vol. 42, Elsevier Science, Amesterdam, Netherlands, 450 pp.

[2] Saadatmanesh H., Ehsani M.R, Li M.W. (1994); Strength and Ductility of Concrete Columns Externally Reinforced with Fiber Composites Strips, ACI Structural Journal, Vol.91(4), 1994, pp. 434 - 447.

[3] Matthys S., Taerwe L. and Audenaert K. (1999); Tests on Axially Loaded Concrete Columns Confined by Fiber Reinforced Polymer Sheet Wrapping , $4^{\text {th }}$ International Symposium on Fiber Reinforced Polymer Reinforcement for Reinforced Concrete Structures, 31 October-5 November 1999, Baltimore, Maryland, USA, pp. 217-228.

[4] SIKA (2001); Sika Wrap System, P.C. 26: Specification for Structural Strengthening with Sika Wrap System, February 2001.

[5] CEB (2001); CEB-FIP Model Code 2000, Design Code - Externally Bonded FRP Reinforcement for R.C. Structures.

[6] Mirmiran A., Shahawy M., Samaan M., El Echary H., Mastrapa J.C., Pico O. (1998); Effect of Column Parameters on FRP-Confined Concrete, ASCE Journal of Composites for Constructions, Vol.2, No. 4, 1998, pp. 175 - 185.

[7] Restrepol J.L., De Vino B. (1996); Enhancement of the Axial Load Carrying Capacity of R. C. Columns by Means of Fiber glass- Epoxy Jackets, $2^{\text {nd }}$ International Conference On Advanced Composite Materials in Bridges and Structures, October 1996, Montreal, Quebec, Canada, pp. 547-554.

[8] CEB (1993); CEB-FIP Model Code 1990, Design Code, Comite EuroInternational du Beton, Lausanne, Switzerland, Thomas Telford, $437 \mathrm{pp}$.

[9] Mander J.B., Priestly M.J.N., Park R. (1988); Theoretical Stress-Strain Model for Confined Concrete, Journal of Structural Engineering, ASCE, Vol. 114(8), 1988, pp. $1804-1826$.

[10] Spoelstra M. R., Monti G. (1999); FRP-Confined Concrete Model, Journal of Composites for Construction, ASCE, Vol. 3, No.3, 1999, pp. 143 - 150.

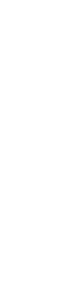




\section{سلوك الأعمدة الخرسانية المسلحة المحزمة برقائق آلياف الكربون

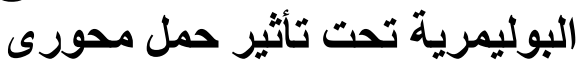

فـى هذا البحث تم عمل در اسـة معمليـة و نظريـة لسـلوك الأعمدة الخرسـانية المسلحة المقواة

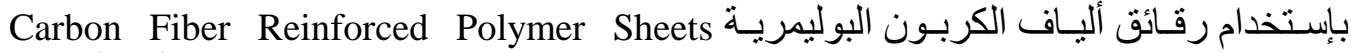

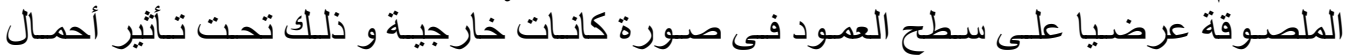

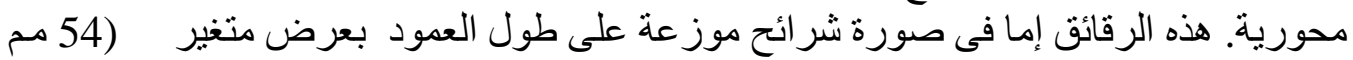

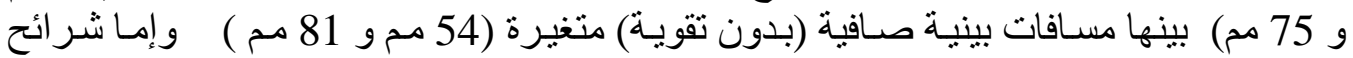

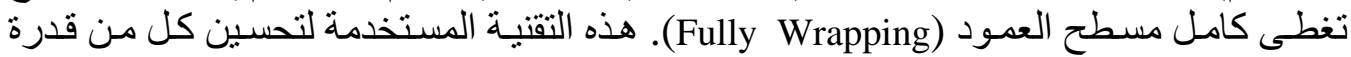
العمود لتحمل الأحمال الو اقعة عليهاو ومطول ملية تلك الأعمدة.

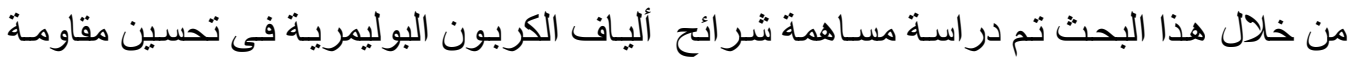

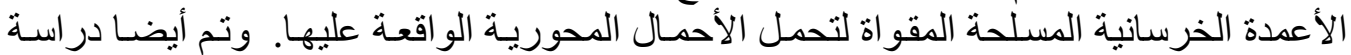

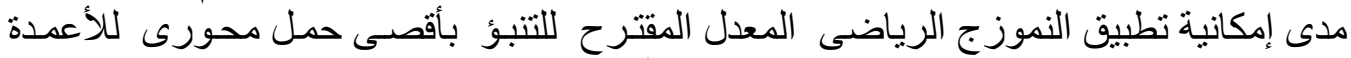

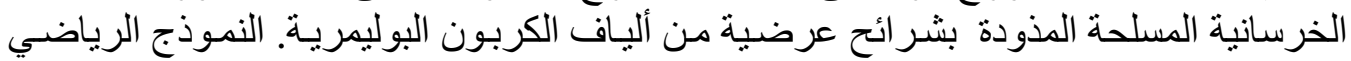

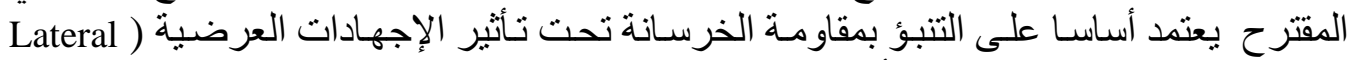
(Stresses

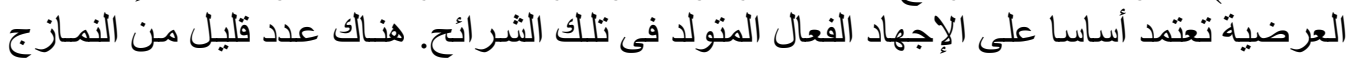

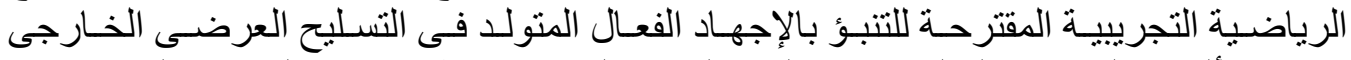

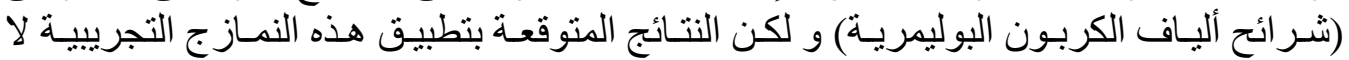

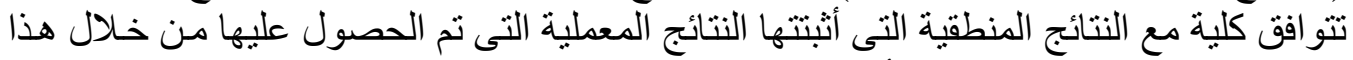

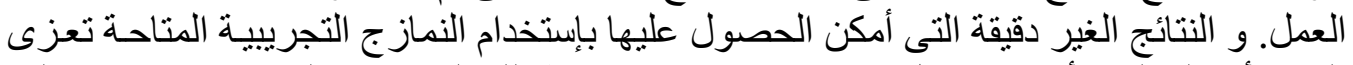

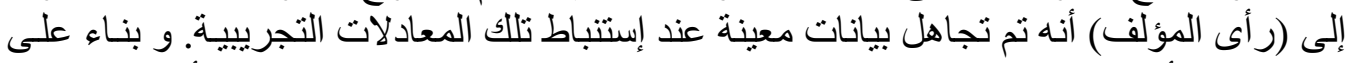

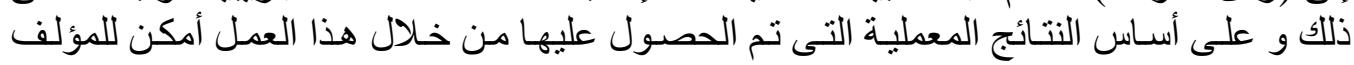

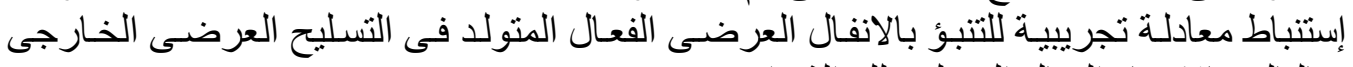

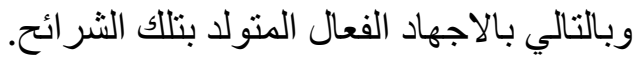

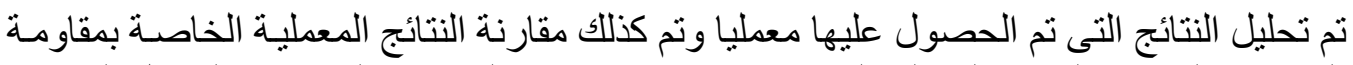

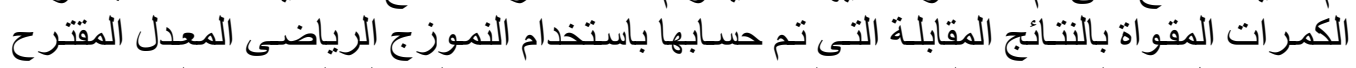

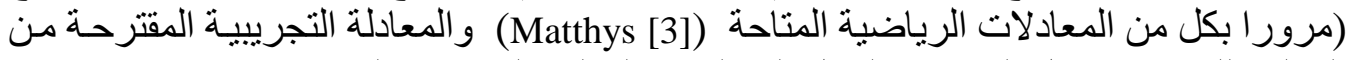

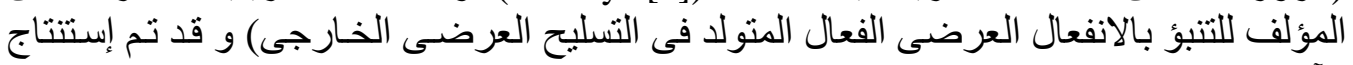

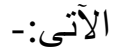

هاهمت شر ائح ألياف الكربون البوليمرية في تحسين مقاومة الأعمدة الخرسـانية المسلحة

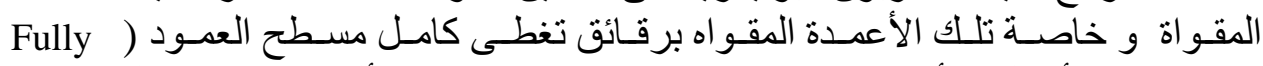
(Wrapping

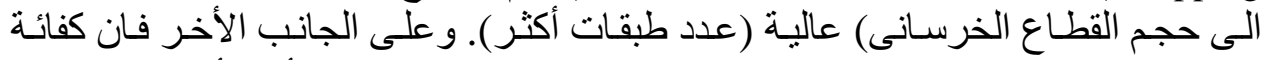

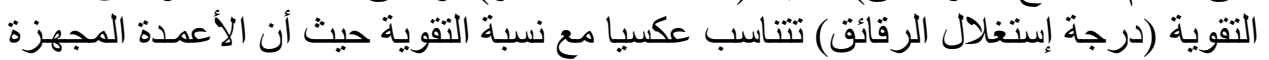

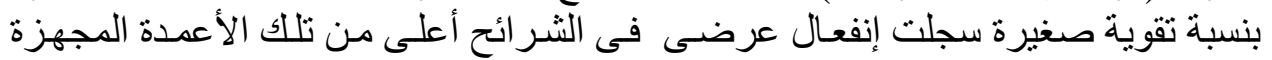

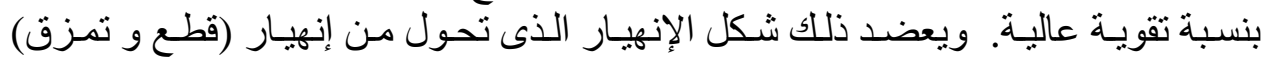




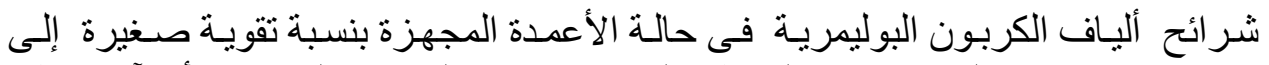

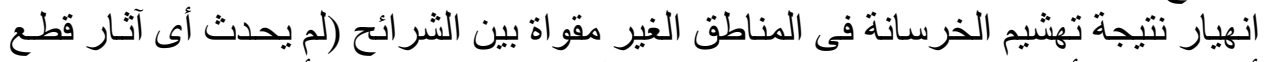

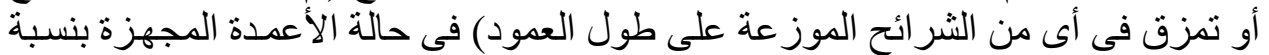

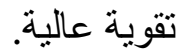

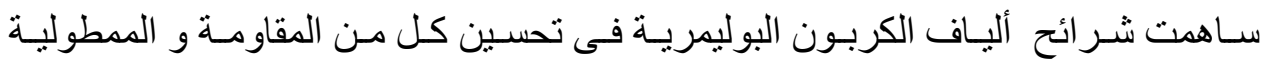

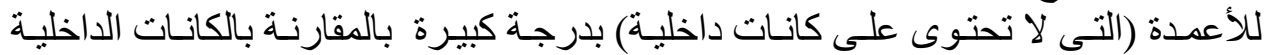

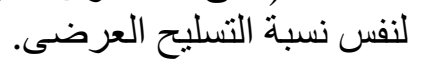

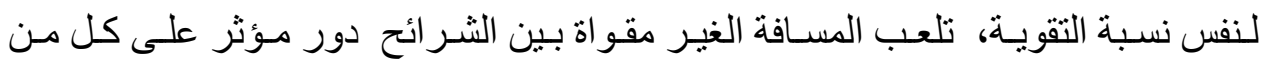

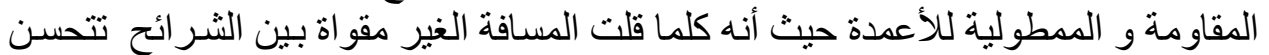

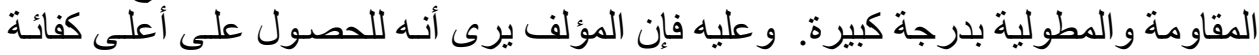

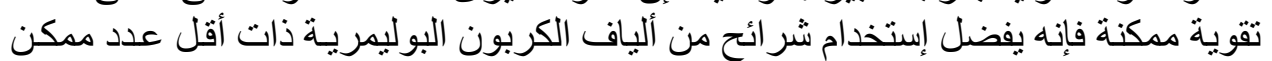

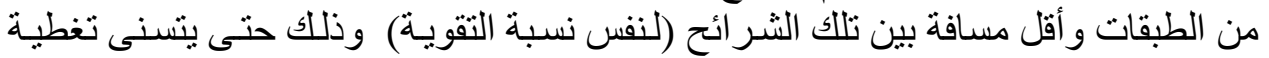
أكبر مساحة سطحية ممكنة من العمود.

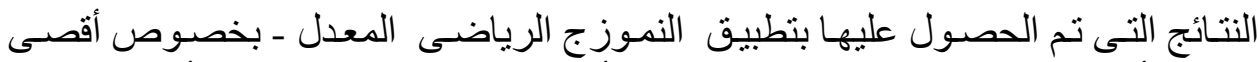

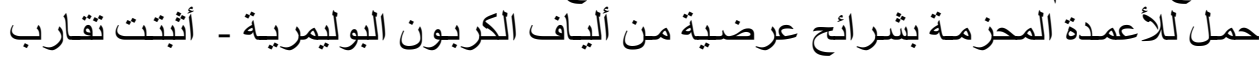

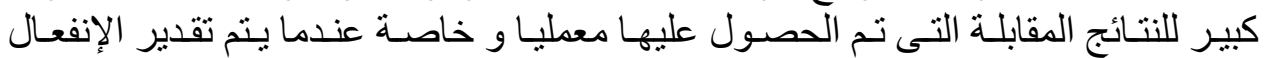

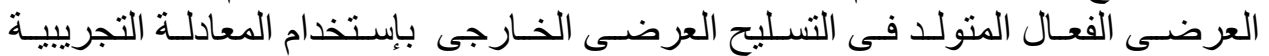

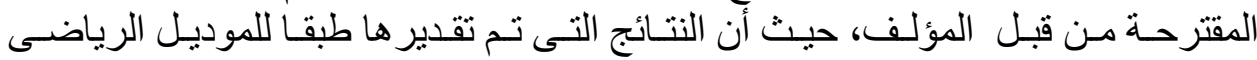

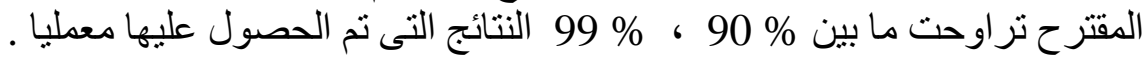

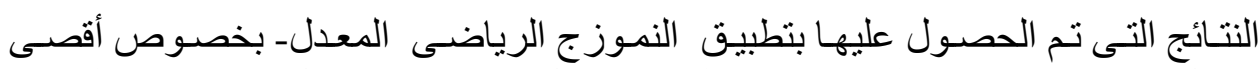

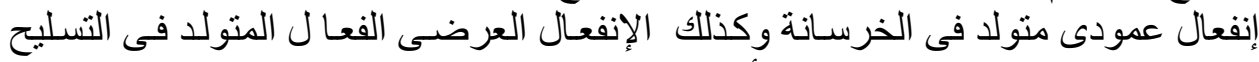

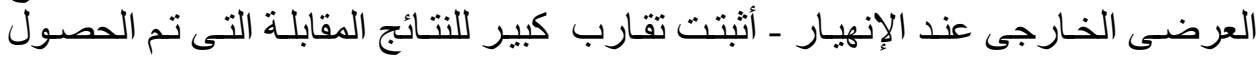

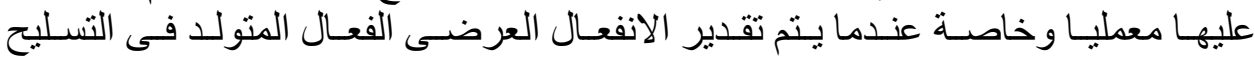

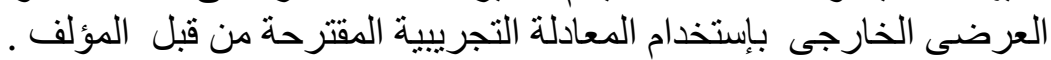

